\title{
Free vibration analysis of isotropic plate with stiffeners using finite element method
}

\author{
Devesh Pratap Singh Yadav*, Avadesh K Sharma and Vaibhav Shivhare
}

Department of Mechanical Engineering, Madhav Institute of Technology and Science, Gwalior, India

\begin{tabular}{|c|c|}
\hline ART I C L E I N F O & A B S T R A C T \\
\hline $\begin{array}{l}\text { Article history: } \\
\text { Received } 6 \text { January, } 2015 \\
\text { Accepted } 5 \text { May } 2015 \\
\text { Available online } \\
6 \text { May } 2015 \\
\text { Keywords: } \\
\text { Stiffened plate } \\
\text { Stiffeners } \\
\text { Finite element method } \\
\text { Free vibration }\end{array}$ & $\begin{array}{l}\text { This paper presents the free vibration analysis of stiffened isotropic plate by means of finite } \\
\text { element method. Stiffeners are used in plates to increase the strength and stiffness. The effect } \\
\text { of position of stiffeners on isotropic plate has been studied which involve the possible } \\
\text { combination of clamped and free edge condition. The model has been discretized using a 20- } \\
\text { node solid element (SOLID186) from the ANSYS element library. The natural frequencies are } \\
\text { calculated using Block-Lanczos algorithm. The comparisons of stiffened plate with the } \\
\text { available results are found to be in good uniformity. The effect of different boundary } \\
\text { conditions, stiffeners location, thickness ratio, stiffener thickness to plate thickness and aspect } \\
\text { ratio on the vibration analysis of stiffened plates has been studied. }\end{array}$ \\
\hline
\end{tabular}

\section{Introduction}

Stiffened plate improves the strength to weight ratio and makes the structure cost efficient. Stiffened plates have been widely used in many industrial structures such as aerospace structures, decks and aircraft structures etc. Barton (1951) studied the free vibration problem of skew cantilever plate. Dawe (1966) employed the Parallelogram elements for rhombic cantilever plate problems. Leissa (1973) attempts to present comprehensive and accurate analytical results for the free vibration of rectangular plates. Liu and Chen (1992) investigated the free vibration of a skew cantilever plate with stiffeners by means of a finite element method is described. As the angle of skew is increased, the natural frequency parameters of the modes are generally increased. Mustafa and Ali (1987) studied the application of structural symmetry techniques to the free vibration analysis of cylindrical and conical shells for the prediction of natural frequencies and mode shapes. Gorman (1976) analyzed the first five symmetric and antisymmetric free vibration modes of a cantilever plate for a wide range of aspect ratios. It is shown that it lends itself readily to the entire family of rectangular plates with classical edge conditions: i.e., clamped, and free. Liu and Chang (1990) shows the deflections and natural frequencies of a cantilever plate with stiffeners obtained by a finite element method are presented. Nair and Rao

* Corresponding author.

E-mail addresses: dpsbeinghuman@gmail.com (D. P. S. Yadav) 
(1984) investigated the effect of stiffener length of a rectangular plate with simply supported or clamped boundary conditions. The effect of this gap between the stiffener tip and the supporting edge on the natural frequencies is investigated hereby using a finite element approach. Liu and Chang (1989) studied to investigate, by a finite element analysis of a cantilever plate, the minimum number of elements in the chord wise direction necessary in order to achieve sufficient accuracy for the first ten Eigen values. The minimum number of elements in the chord wise has been determined, and it has also been found that, with a new, modified element, one chord wise element will provide sufficient accuracy. Mizusawa et al. (1979) presented vibration analysis of isotropic rectangular plates with free edges by the Rayleigh-Ritz method with B-spline functions. Accurate frequencies of rectangular plates are analyzed for different aspect ratios and boundary conditions. The effects of Poisson's ratio on natural frequencies of square plates with free edges are also investigated. Laura and Gutierrez (1976) deals with the determination of the fundamental frequency of vibration of rectangular plates with edged elastically restrained against rotation. Wu and Liu (1988) analyzed the free vibration of stiffened plates with elastically edges restrained and intermediate stiffeners by using the Rayleigh-Ritz method. Aksu and Ali (1976) studied the free vibration characteristics of rectangular stiffened plates having a single stiffener have been examined by using the finite difference method. Gupta et.al (1986) studied the free vibration characteristics of a damped stiffened panel with applied viscoelastic damping on the flanges of the stiffeners are studied using finite element method. Sivakumaran (1987) concerned with the estimation of natural frequencies of undamaged laminated rectangular plates having completely free edges. The Rayleigh-Ritz energy approach is employed here to obtain the approximate natural frequencies of symmetrically laminated plates. Mukherjee and Mukhopadhyay (1988) studied an isoparametric stiffened plate element is introduced for the free vibration analysis of eccentrically stiffened plates. Bardell and Mead (1989) studied the hierarchical finite element method is used to establish the stiffness and mass matrices of a cylindrically curved rectangular panel. Some natural frequencies and modes of two such panels, each with different boundary conditions, are then determined. The vibration analysis of stiffened plates and the effects of various parameters such as the boundary conditions of the plate, along with orientation, eccentricity, dimensions and number of the stiffeners on free vibration characteristics of stiffened panels have been studied by Hamedani et al. (2012). Samanta and Mukhopadhyay (2004) studied the development of a new stiffened shell element and subsequent application of this element in determining natural frequencies and mode shapes of the different stiffened structures. Qing et al. (2006) studied the free vibration analysis of stiffened laminated plates is developed by separate consideration of plate and stiffeners. The method accounts for the compatibility of displacements and stresses on the interface between the plate and stiffeners, the transverse shear deformation, and naturally the rotary inertia of the plate and stiffeners. Sharma and Mittal (2010, 2011, 2013 and 2014) studied the free vibration analysis of laminated composite plates with elastically restrained edges by applying FEM. In this paper the effects of different geometric parameters i.e. aspect ratio, skew angle, thickness ratio, boundary conditions, stiffener thickness to plate thickness, stiffeners location on the free vibration responses of isotropic plate are studied in detail.
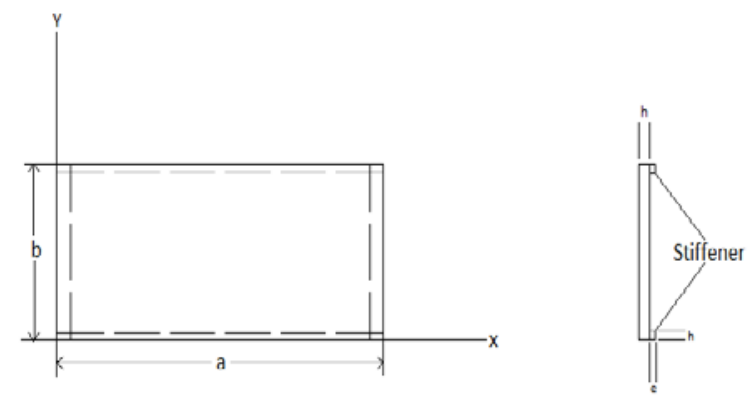

Fig. 1. Sketch of Plate with stiffeners
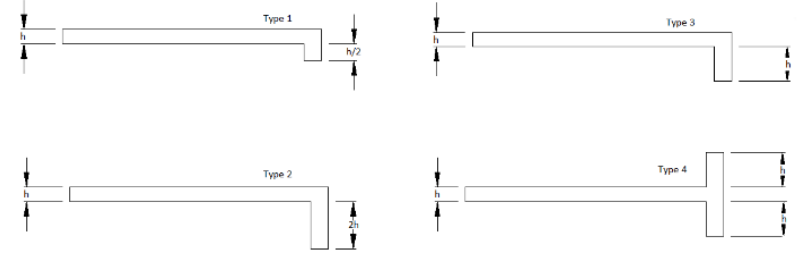

Fig. 2. Different types of stiffeners 


\section{Material Properties}

Consider a thin stiffened plate as shown in Fig. 1, here $a$ and $b$ are geometric dimensions, $h$ is the thickness of the plate and $\alpha$ is the skew angle. The stiffeners are located along the upper, lower and all edges of the plate respectively. Fig. 2 shows the different types of stiffeners which are considered for the study of vibration analysis of plate. To show the computational efficiency of FEM, an isotropic stiffened plate has been considered. The default material properties of isotropic plate are

$$
E_{x}=200 e 9, v=0.3, \rho=7860 \mathrm{~kg} / \mathrm{m}^{3}, \frac{h}{a}=0.5, \frac{a}{b}=1, \frac{e}{h}=1
$$

\subsection{Plate Element}

The SOLID186 is a higher order 3-D 20-node solid element that exhibits quadratic displacement behavior. The element is defined by 20 nodes having three degrees of freedom per node: translations in the nodal $\mathrm{x}, \mathrm{y}$, and $\mathrm{z}$ directions. The element supports plasticity, hyperelasticity, creep, stress stiffening, large deflection, and large strain capabilities. It also has mixed formulation capability for simulating deformations of nearly incompressible elastoplastic materials, and fully incompressible hyperelastic materials. The geometry, node locations, and the element coordinate system for this element are shown in Fig. 3.
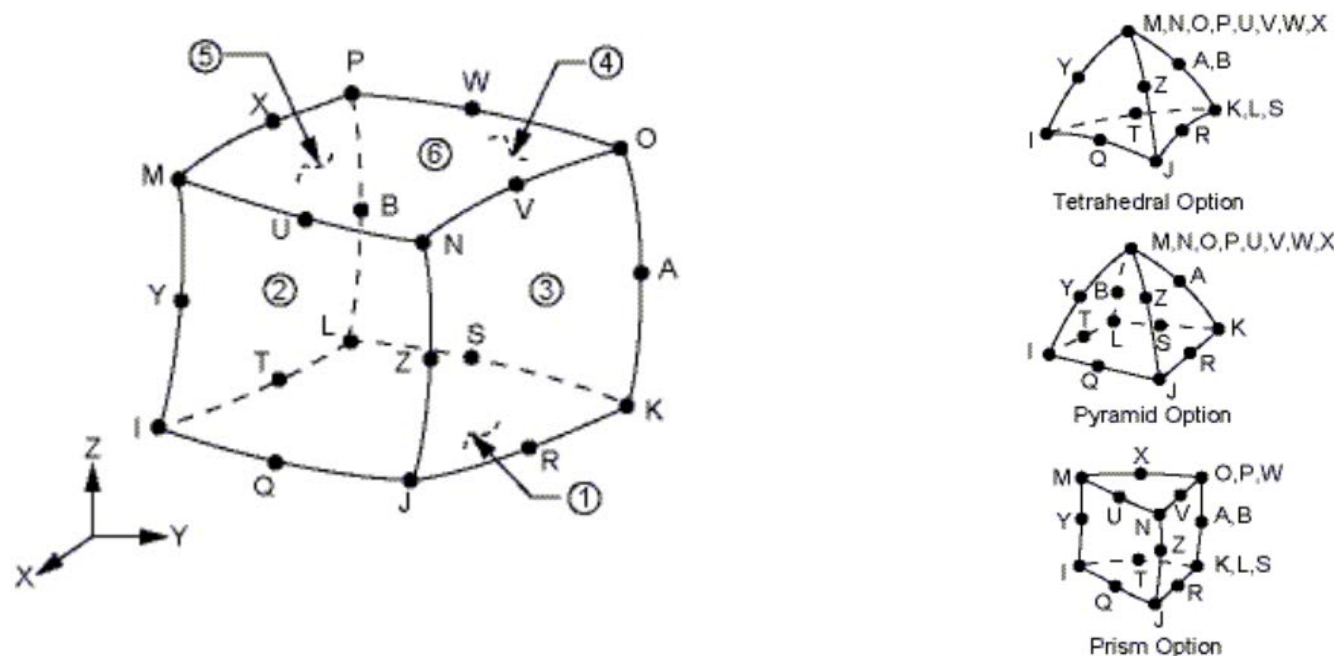

Fig. 3. SOLID186 element

\section{Numerical results and discussion}

The study shows the vibration analysis of different types of stiffened isotropic plates. Table 1 shows the comparison of non dimensional fundamental frequencies for the isotropic skew plate for the different skew angles. The results are compared with Barton (1951), Dawe (1966), Liessa (1973) and Liu et al. (1992) are found in good conformity.

Table 2 shows the comparison of the first ten non-dimensional frequencies of isotropic skew plate without stiffener for the boundary condition (CFFF- i.e. clamped-free-free-free-free) and the results are compared for the skew angle, $\alpha=0,15,30,45$ and 60 with the Liu and Chen (1992). 
Table 1. Comparison of non-dimensional frequency parameters $\bar{\omega}_{i}=\omega_{i} * a^{2} \sqrt{\frac{\rho}{D}}$ for skew plates; a/b $=1$ and $v=0.3(\mathrm{CFFF})$

\begin{tabular}{|c|c|c|c|c|c|c|}
\hline $\begin{array}{l}\text { Skew } \\
\text { Angle }\end{array}$ & Mode & $\begin{array}{l}\text { Barton } \\
\text { (1951) }\end{array}$ & Dawe (1966) & $\begin{array}{l}\text { Leissa } \\
\text { (1973) }\end{array}$ & $\begin{array}{c}\text { Liu et al. } \\
\text { (1992) }\end{array}$ & $\begin{array}{l}\text { Present } \\
\text { results }\end{array}$ \\
\hline \multirow{6}{*}{0} & 1 & 3.43 & 3.47 & 3.4917 & 3.4750 & 3.4692 \\
\hline & 2 & 8.32 & 8.52 & 8.5264 & 8.5176 & 8.4781 \\
\hline & 3 & - & 21.54 & 21.429 & 21.3251 & 21.2584 \\
\hline & 4 & - & - & - & - & 27.1316 \\
\hline & 5 & - & - & - & - & 30.8420 \\
\hline & 6 & - & - & - & - & 53.9143 \\
\hline \multirow{6}{*}{15} & 1 & 3.44 & 3.59 & - & 3.5884 & 3.5810 \\
\hline & 2 & 8.68 & 8.71 & - & 8.7130 & 8.6678 \\
\hline & 3 & - & 21.59 & - & 22.2818 & 22.1968 \\
\hline & 4 & - & - & - & - & 26.2676 \\
\hline & 5 & - & - & - & - & 33.7346 \\
\hline & 6 & - & - & - & - & 51.8408 \\
\hline \multirow{6}{*}{30} & 1 & 3.88 & 3.95 & - & 3.9383 & 3.9249 \\
\hline & 2 & 9.33 & 9.42 & - & 9.4618 & 9.3808 \\
\hline & 3 & - & 25.56 & - & 25.4436 & 25.2391 \\
\hline & 4 & - & - & - & - & 25.8722 \\
\hline & 5 & - & - & - & - & 41.1649 \\
\hline & 6 & - & - & - & - & 50.4585 \\
\hline \multirow{6}{*}{45} & 1 & 4.33 & 4.59 & - & 4.5469 & 4.5060 \\
\hline & 2 & 11.21 & 11.14 & - & 11.4237 & 11.2189 \\
\hline & 3 & - & 27.48 & - & 27.4364 & 26.9349 \\
\hline & 4 & - & - & - & - & $31 . .4509$ \\
\hline & 5 & - & - & - & - & 50.5120 \\
\hline & 6 & - & - & - & - & 58.8470 \\
\hline
\end{tabular}

Table 2. Comparison of Natural frequency parameters of skew plates without stiffener for different skew angle; $\mathrm{a} / \mathrm{b}=2$ and $v=0.3$ (CFFF).

\begin{tabular}{ll|ccccccccccc}
\hline $\begin{array}{l}\text { Skew } \\
\text { angle }\end{array}$ & & & \multicolumn{1}{c}{$\bar{\omega}_{i}=\omega_{i} * a^{2} \sqrt{\frac{\rho}{D}}$} & & & & \\
\hline$\alpha$ & & & & & & & & & & \\
\hline 0 & Liu-Chen & 3.4292 & 14.529 & 21.340 & 47.502 & 60.262 & 92.116 & 92.936 & 119.254 & 127.096 & 153.35 \\
& Present & 3.4368 & 14.706 & 21.408 & 47.858 & 60.027 & 91.895 & 92.808 & 118.015 & 126.103 & 143.62 \\
\hline 15 & Liu-Chen & 3.4989 & 14.780 & 22.218 & 46.818 & 63.681 & 88.986 & 99.859 & 123.989 & 138.168 & 147.98 \\
& Present & 3.5063 & 14.920 & 22.292 & 46.994 & 63.479 & 88.468 & 99.571 & 122.676 & 136.602 & 142.13 \\
\hline 30 & Liu-Chen & 3.7096 & 15.735 & 25.041 & 46.739 & 73.360 & 86.541 & 120.227 & 138.765 & 146.644 & 170.88 \\
& Present & 3.7149 & 15.769 & 24.994 & 46.595 & 72.604 & 85.283 & 119.105 & 135.005 & 136.803 & 143.12 \\
\hline 45 & Liu-Chen & 4.0846 & 17.868 & 31.004 & 49.709 & 88.620 & 94.427 & 142.561 & 164.303 & 200.859 & 209.86 \\
& Present & 4.0568 & 17.772 & 29.944 & 49.183 & 84.049 & 92.104 & 124.959 & 133.101 & 155.345 & 188.34 \\
\hline 60 & Liu-Chen & 4.7479 & 22.034 & 44.834 & 60.173 & 107.94 & 141.330 & 184.960 & 244.481 & 292.234 & 371.40 \\
& Present & 4.5139 & 21.417 & 39.798 & 56.518 & 96.412 & 101.990 & 122.565 & 149.989 & 200.530 & 214.85 \\
\hline
\end{tabular}


Table 3 shows the comparison of the first ten non-dimensional frequencies of isotropic skew plate with stiffener located along upper edge for the boundary condition (CFFF) and the results are compared for the skew angle, $\alpha=0,15,30$ and 45 with the Liu and Chen (1992).

Table 3. Comparison of natural frequency parameters of skew plates with stiffener located along upper edge for different skew angle; $\mathrm{a} / \mathrm{b}=2$ and $v=0.3$ (CFFF)

\begin{tabular}{|c|c|c|c|c|c|c|c|c|c|c|c|}
\hline \multicolumn{2}{|c|}{ Skew angle } & \multicolumn{10}{|c|}{$\bar{\omega}_{i}=\omega_{i} * a^{2} \sqrt{\frac{\rho}{D}}$} \\
\hline$\alpha$ & & $i=1$ & 2 & 3 & 4 & 5 & 6 & 7 & 8 & 9 & 10 \\
\hline \multirow[t]{2}{*}{0} & Liu-Chen & 4.3564 & 14.5808 & 26.1385 & 52.9751 & 67.9598 & 85.2916 & 111.8705 & 120.9210 & 130.5247 & 181.087 \\
\hline & Present & 3.7741 & 15.0347 & 23.4841 & 50.2775 & 64.7753 & 90.5415 & 100.6826 & 122.7337 & 128.3659 & 145.369 \\
\hline \multirow[t]{2}{*}{15} & Liu-Chen & 4.3997 & 16.0985 & 25.8962 & 53.9236 & 68.5468 & 91.7526 & 112.8031 & 125.2906 & 136.5247 & 182.959 \\
\hline & Present & 3.9138 & 15.0861 & 25.1457 & 48.6607 & 69.8191 & 95.2315 & 97.5024 & 127.0699 & 143.1517 & 143.945 \\
\hline \multirow[t]{2}{*}{30} & Liu-Chen & 4.8835 & 18.7688 & 27.7397 & 54.4217 & 76.1127 & 104.707 & 122.5785 & 139.2412 & 162.2579 & 186.824 \\
\hline & Present & 4.2382 & 15.8747 & 28.8965 & 48.0683 & 79.9602 & 92.4380 & 117.9615 & 137.8693 & 142.3166 & 151.840 \\
\hline \multirow[t]{2}{*}{45} & Liu-Chen & 6.2117 & 22.2936 & 32.8171 & 58.2128 & 91.7804 & 116.0766 & 159.9638 & 170.3824 & 195.4136 & 246.140 \\
\hline & Present & 4.7566 & 18.0708 & 35.1617 & 50.9728 & 91.3561 & 102.3323 & 125.2721 & 138.7990 & 172.7521 & 192.836 \\
\hline
\end{tabular}

Table 4 shows the comparison of the first ten non-dimensional frequencies of isotropic skew plate with stiffener located along upper edge with different type of stiffeners and the results are compared with the Liu and Chen (1992).

Table 4. Comparison of natural frequency parameters of skew plates with different types of stiffener located along upper edge; $\mathrm{a} / \mathrm{b}=2, v=0.3$ and $\alpha=30$ (CFFF)

\begin{tabular}{|c|c|c|c|c|c|c|c|c|c|c|}
\hline \multirow{2}{*}{$\begin{array}{l}\text { Skew } \\
\text { angle }\end{array}$} & \multicolumn{10}{|c|}{$\bar{\omega}_{i}=\omega_{i} * a^{2} \sqrt{\frac{\rho}{\rho}}$} \\
\hline & $i=1$ & 2 & 3 & 4 & 5 & 6 & 7 & 8 & 9 & 10 \\
\hline \multirow{2}{*}{$\begin{array}{l}\text { Type1 Liu \& Chen (1992) } \\
\text { (Present) }\end{array}$} & 4.2496 & 17.9674 & 25.9397 & 49.7959 & 74.8985 & 93.4623 & 121.9020 & 138.3669 & 154.2560 & 176.9327 \\
\hline & 3.8709 & 15.7991 & 26.2869 & 46.9698 & 76.0313 & 86.6743 & 118.2289 & 137.2645 & 141.0782 & 143.4808 \\
\hline \multirow{2}{*}{$\begin{array}{l}\text { Type2 Liu \& Chen (1992) } \\
\text { (Present) }\end{array}$} & 4.8835 & 18.7688 & 27.7397 & 54.4217 & 76.1127 & 104.7073 & 122.5785 & 139.2412 & 162.2579 & 186.8242 \\
\hline & 4.2374 & 15.8715 & 28.8924 & 48.0559 & 79.9314 & 92.4134 & 117.9244 & 137.8651 & 142.2342 & 151.7706 \\
\hline \multirow{2}{*}{$\begin{array}{l}\text { Type3 Liu \& Chen (1992) } \\
\text { (Present) }\end{array}$} & 6.7270 & 19.8983 & 30.6577 & 66.2300 & 81.2645 & 109.2392 & 127.0319 & 143.5953 & 175.4043 & 197.9770 \\
\hline & 5.5099 & 16.3446 & 34.8157 & 53.8073 & 82.4122 & 108.0014 & 121.4337 & 138.6921 & 142.8308 & 166.9966 \\
\hline \multirow{2}{*}{$\begin{array}{l}\text { Type4 Liu \& Chen (1992) } \\
\text { (Present) }\end{array}$} & 5.4461 & 18.4342 & 29.0272 & 57.0872 & 76.2690 & 105.2199 & 122.4044 & 136.9742 & 164.2620 & 188.4013 \\
\hline & 4.7241 & 15.9270 & 31.8088 & 49.5534 & 81.1450 & 100.5632 & 117.3979 & 138.8114 & 141.0247 & 157.7153 \\
\hline
\end{tabular}

Table 5 shows the first ten non-dimensional frequencies of isotropic skew plate with stiffener located along all edge for the boundary condition (CFFF), $\mathrm{a} / \mathrm{b}=0.5$ and $\mathrm{e} / \mathrm{h}=0.5$. It is observed from the results that as the skew angle increases the frequency parameter increases. Table 6 shows the first ten non-dimensional frequencies of isotropic skew plate with stiffener located along upper edge for the boundary condition (CFFF), $\mathrm{a} / \mathrm{b}=1$ and $\mathrm{a} / \mathrm{b}=2$ and $\mathrm{e} / \mathrm{h}=0.5$. It is clear from the results that as the skew angle increases the frequency parameter increases and also observed that as the aspect ratio increases the natural frequency parameter increases. 
Table 5. Natural frequency parameters of skew plates with stiffener located along all edges for different skew angle; a $/ \mathrm{b}=0.5$ and $v=0.3$ and $\mathrm{e} / \mathrm{h}=0.5$ (CFFF)

\begin{tabular}{l|cccccccccc}
\hline $\begin{array}{l}\text { Skew } \\
\text { angle }\end{array}$ & \multicolumn{10}{c}{$\bar{\omega}_{i}=\omega_{i} * a^{2} \sqrt{\frac{\rho}{D}}$} \\
\hline$\alpha$ & $i=1$ & 2 & 3 & 4 & 5 & 6 & 7 & 8 & 9 & 10 \\
\hline 0 & 5.1746 & 8.0972 & 15.6309 & 29.7562 & 32.3681 & 37.7260 & 48.9017 & 51.5120 & 65.8319 & 80.3270 \\
15 & 5.3922 & 8.3285 & 15.9372 & 30.0636 & 34.2106 & 39.5215 & 50.8480 & 51.5701 & 68.9170 & 78.2285 \\
30 & 6.1213 & 9.3133 & 17.1491 & 31.4403 & 40.2580 & 46.0615 & 52.6389 & 58.9281 & 77.6218 & 79.0033 \\
45 & 7.3820 & 12.1758 & 20.3657 & 35.3111 & 49.4434 & 55.8973 & 68.2845 & 75.0380 & 87.8922 & 98.1697 \\
60 & 8.8639 & 20.9194 & 29.3528 & 45.1321 & 60.4522 & 74.0790 & 94.5125 & 118.297 & 131.855 & 143.856 \\
\hline
\end{tabular}

Table 6. Natural frequency parameters of skew plates with stiffener located along upper edge for different skew angle, $v=0.3$ and $\mathrm{e} / \mathrm{h}=0.5(\mathrm{CFFF})$

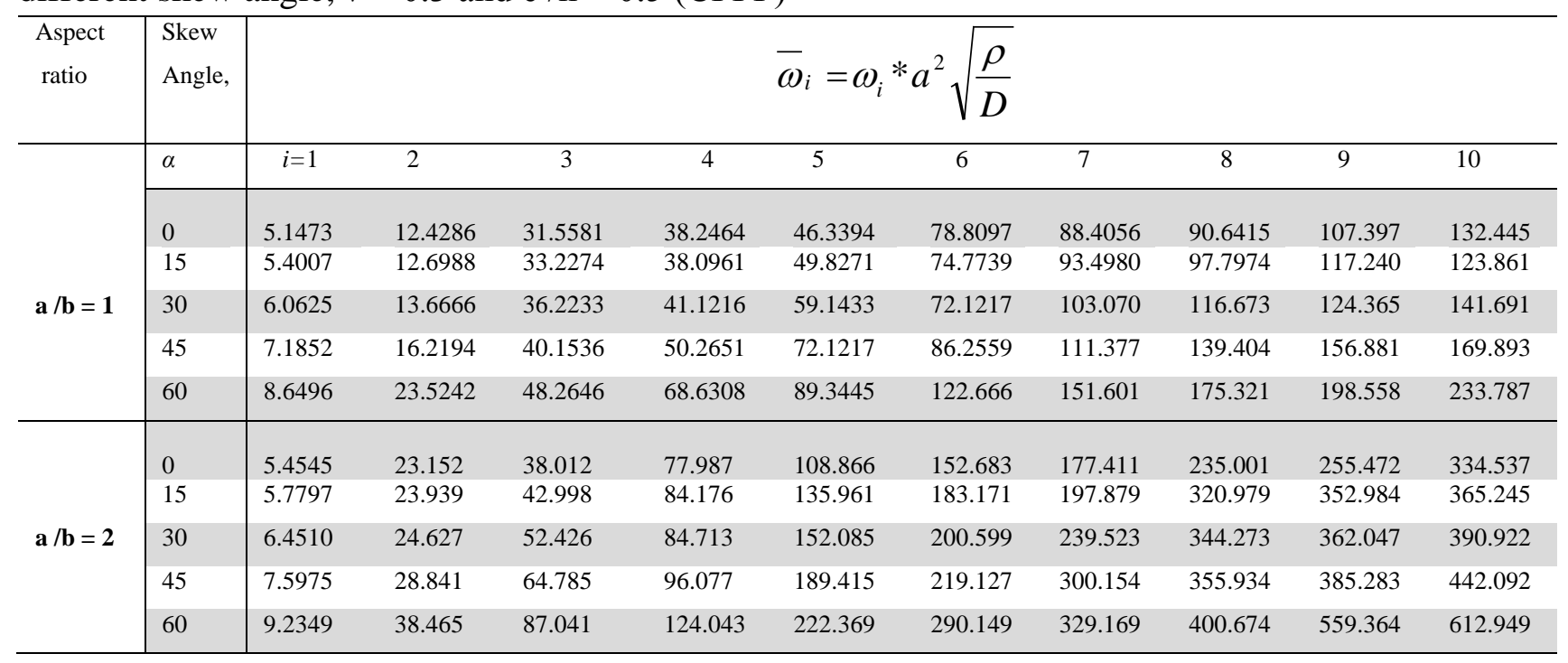

Table 7 shows the first ten non-dimensional frequencies of isotropic skew plate with stiffener located along all edge for the boundary condition (CFFF), $a / b=1$ and $e / h=0.5$. It is examined from the results that as the skew angle increases the frequency parameter increases.

Table 7. Natural frequency parameters of skew Plates with stiffener located along all edges for different skew angle; $\mathrm{a} / \mathrm{b}=1$ and $v=0.3$ and $\mathrm{e} / \mathrm{h}=0.5(\mathrm{CFFF})$

\begin{tabular}{l|cccccccccc}
\hline $\begin{array}{l}\text { Skew } \\
\text { angle }\end{array}$ & \multicolumn{10}{c}{$\bar{\omega}_{i}=\omega_{i} * a^{2} \sqrt{\frac{\rho}{D}}$} \\
\hline$\alpha$ & $i=1$ & 2 & 3 & 4 & 5 & 6 & 7 & 8 & 9 & 10 \\
\hline 0 & 5.3833 & 12.9215 & 33.520 & 40.9275 & 49.4284 & 83.8429 & 93.486 & 96.8877 & 114.283 & 141.729 \\
15 & 5.5525 & 13.1536 & 35.0240 & 40.5448 & 52.6218 & 80.4211 & 99.053 & 103.715 & 122.469 & 132.138 \\
30 & 6.1591 & 14.1906 & 39.9841 & 41.4024 & 62.8760 & 78.4068 & 116.483 & 120.530 & 127.071 & 150.705 \\
45 & 7.2830 & 16.9798 & 44.5045 & 50.3877 & 82.3591 & 87.2957 & 127.613 & 143.356 & 170.988 & 181.923 \\
60 & 8.8127 & 24.7879 & 52.6220 & 70.3529 & 100.8928 & 136.1817 & 160.930 & 193.262 & 216.123 & 269.285 \\
\hline
\end{tabular}


Table 8 shows the first ten non-dimensional frequencies of isotropic skew plate with stiffener located along upper edge for the boundary condition (CCFF- i.e. clamped-clamped-free-free), $\mathrm{a} / \mathrm{b}=0.5$ and $\mathrm{e} / \mathrm{h}=0.5$. It is clear from the results that as the skew angle increases the frequency parameter increases.

Table 8. Natural frequency parameters of skew plates with stiffener located along upper edge for different skew angle; a $/ \mathrm{b}=0.5$ and $v=0.3$ and $\mathrm{e} / \mathrm{h}=0.5$ (CCFF)

\begin{tabular}{|c|c|c|c|c|c|c|c|c|c|c|}
\hline $\begin{array}{l}\text { Skew } \\
\text { angle }\end{array}$ & \multicolumn{10}{|c|}{$\bar{\omega}_{i}=\omega_{i} * a^{2} \sqrt{\frac{\rho}{D}}$} \\
\hline$\alpha$ & $i=1$ & 2 & 3 & 4 & 5 & 6 & 7 & 8 & 9 & 10 \\
\hline 0 & 31.8571 & 34.5943 & 40.8244 & 52.0429 & 69.8811 & 87.5091 & 91.8131 & 95.1477 & 100.512 & 114.016 \\
\hline 15 & 33.8159 & 36.5532 & 42.6660 & 53.8617 & 71.6858 & 92.8109 & 96.5697 & 98.1551 & 106.673 & 119.395 \\
\hline 30 & 40.0936 & 43.6528 & 49.3005 & 60.5367 & 78.4031 & 101.689 & 111.775 & 119.322 & 127.516 & 132.380 \\
\hline 45 & 52.6271 & 59.8236 & 67.6989 & 78.7949 & 96.4687 & 118.710 & 139.392 & 158.372 & 171.355 & 178.091 \\
\hline 60 & 81.3049 & 92.7783 & 129.752 & 137.662 & 151.302 & 169.694 & 192.515 & 220.491 & 255.070 & 279.339 \\
\hline
\end{tabular}

Table 9 shows the first ten non-dimensional frequencies of isotropic skew plate with stiffener located along upper edge for the boundary condition (CCCC), $\mathrm{a} / \mathrm{b}=2$ and $\mathrm{e} / \mathrm{h}=0.5$. It is observed from the results that as the skew angle increases the frequency parameter increases.

Table 9. Natural frequency parameters of skew plates with stiffener located along upper edge for different skew angle; $\mathrm{a} / \mathrm{b}=2$ and $v=0.3$ and e $/ \mathrm{h}=0.5$ (CCCC)

\begin{tabular}{l|cccccccccc}
\hline $\begin{array}{l}\text { Skew } \\
\text { angle }\end{array}$ & \multicolumn{10}{|c}{$\bar{\omega}_{i}=\omega_{i}{ }^{*} a^{2} \sqrt{\frac{\rho}{D}}$} \\
\hline$\alpha$ & $i=1$ & 2 & 3 & 4 & 5 & 6 & 7 & 8 & 9 & 10 \\
\hline 0 & 144.54 & 185.28 & 258.41 & 363.78 & 378.41 & 418.39 & 487.39 & 500.12 & 587.23 & 666.61 \\
15 & 154.29 & 195.85 & 269.81 & 374.49 & 405.98 & 445.47 & 510.53 & 517.99 & 623.78 & 666.71 \\
30 & 189.35 & 232.43 & 308.48 & 413.80 & 501.31 & 524.18 & 567.56 & 613.23 & 706.76 & 730.16 \\
45 & 282.36 & 328.88 & 409.83 & 522.05 & 652.43 & 753.32 & 792.11 & 816.43 & 926.40 & 935.68 \\
60 & 569.67 & 620.50 & 710.68 & 838.71 & 994.87 & 1165.66 & 1345.14 & 1540.26 & 1563.31 & 1629.59 \\
\hline
\end{tabular}

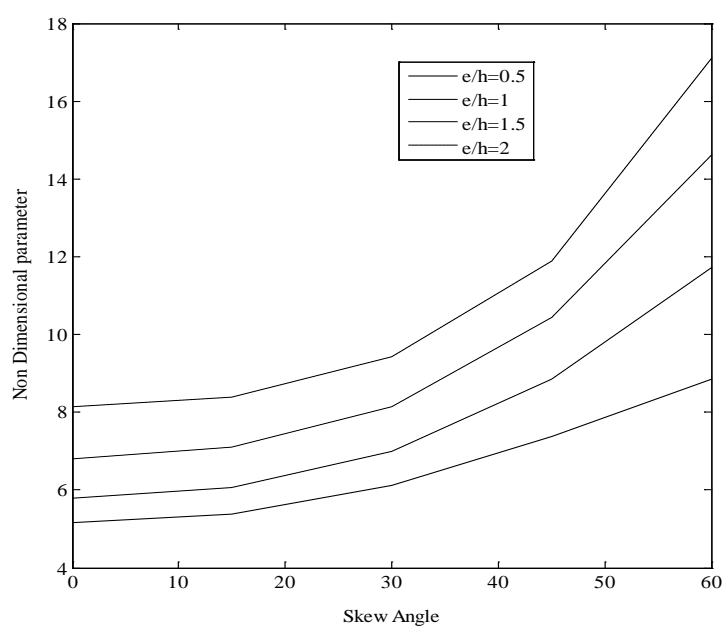

Fig. 4. Variation of frequency parameter with different skew angles for isotropic skew plates with stiffener located at all edges and $\mathrm{a} / \mathrm{b}=0.5$ for CFFF boundary conditions

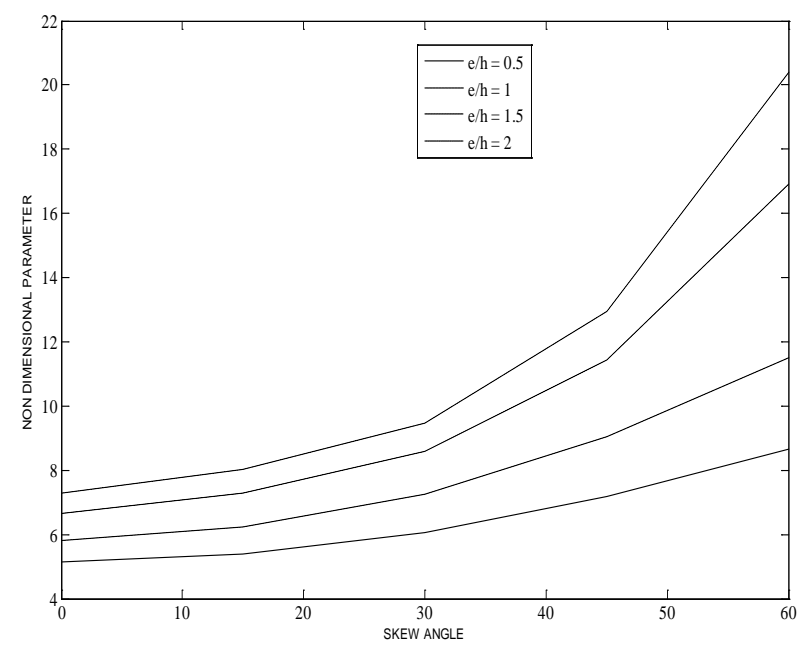

Fig. 5. Variation of frequency parameter with different skew angles for isotropic skew plates with stiffener located at upper edge and $a / b=1$ for CFFF boundary conditions 
Fig. 4 shows the variation of first ten non-dimensional frequencies with different skew angle $(\alpha=0$, $15,30,45$ and 60 ) for a stiffened isotropic plate of aspect ratio $\mathrm{a} / \mathrm{b}=0.5$ and stiffener located at all edges and ratio of stiffener to plate thickness $(\mathrm{e} / \mathrm{h}=0.5,1,1.5,2)$ for CFFF boundary condition. The frequency in all ten modes increases as the skew angle increases. It also shows that as the ratio of stiffener to plate thickness increases, the fundamental frequencies increases. Fig. 5 shows the variation of first ten nondimensional frequencies with different skew angle $(\alpha=0,15,30,45$ and 60) for a stiffened isotropic plate of aspect ratio $\mathrm{a} / \mathrm{b}=1$ and stiffener located at upper edges and ratio of stiffener to plate thickness $(\mathrm{e} / \mathrm{h}=0.5,1,1.5,2)$ for CFFF boundary condition. The frequency in all ten modes increases as the skew angle increases. It also shows that as the ratio of stiffener to plate thickness increases, the fundamental frequencies increases. Fig. 6 shows the variation of first ten non-dimensional frequencies with different skew angle $(\alpha=0,15,30,45$ and 60$)$ for a stiffened isotropic plate of aspect ratio $a / b=1$ and stiffener located at all edges and ratio of stiffener to plate thickness $(\mathrm{e} / \mathrm{h}=0.5,1,1.5,2)$ for CFFF boundary condition. The frequency in all ten modes increases as the skew angle increases. It also shows that as the ratio of stiffener to plate thickness increases, the fundamental frequencies increases. Fig. 7 shows the variation of first ten non-dimensional frequencies with different skew angle $(\alpha=0,15,30,45$ and 60 ) for a stiffened isotropic plate of aspect ratio $a / b=2$ and stiffener located at upper edges and ratio of stiffener to plate thickness $(\mathrm{e} / \mathrm{h}=0.5,1,1.5,2)$ for CFFF boundary condition. The frequency in all ten modes increases as the skew angle increases. It also shows that as the ratio of stiffener to plate thickness increases, the fundamental frequencies increases.

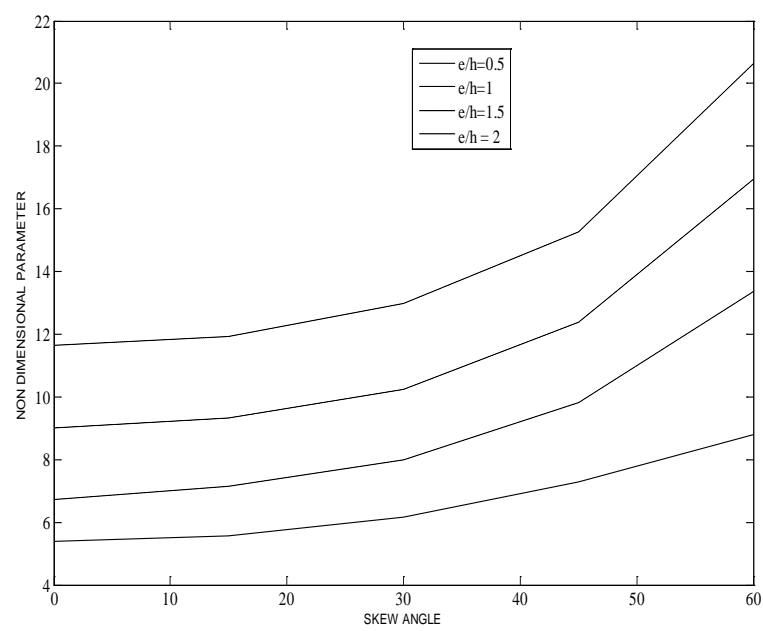

Fig. 6. Variation of frequency parameter with different skew angles for isotropic skew plates with stiffener located at all edges and $\mathrm{a} / \mathrm{b}=1$ for CFFF boundary conditions

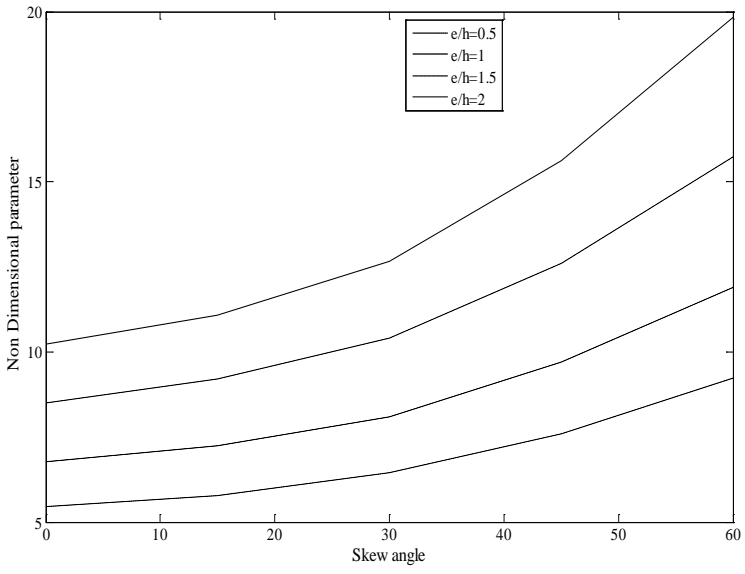

Fig. 7. Variation of frequency parameter with different skew angles for isotropic skew plates with stiffener located at upper edge and $\mathrm{a} / \mathrm{b}=2$ for CFFF boundary conditions

Fig. 8 shows the variation of first ten non-dimensional frequencies with different skew angle $(\alpha=0$, $15,30,45$ and 60 ) for a stiffened isotropic plate of aspect ratio $\mathrm{a} / \mathrm{b}=0.5$ and stiffener located at upper edges and ratio of stiffener to plate thickness $(\mathrm{e} / \mathrm{h}=0.5,1,1.5,2)$ for CCFF boundary condition. The frequency in all ten modes increases as the skew angle increases. It also shows that as the ratio of stiffener to plate thickness increases, the fundamental frequencies increases. Fig. 9 shows the variation of first ten non-dimensional frequencies with different skew angle $(\alpha=0,15,30,45$ and 60) for a stiffened isotropic plate of aspect ratio $\mathrm{a} / \mathrm{b}=2$ and stiffener located at upper edges and ratio of stiffener to plate thickness $(\mathrm{e} / \mathrm{h}=0.5,1,1.5,2)$ for fully clamped boundary condition. The frequency in all ten modes increases as the skew angle increases. It also shows that as the ratio of stiffener to plate thickness increases, the fundamental frequencies increases. 


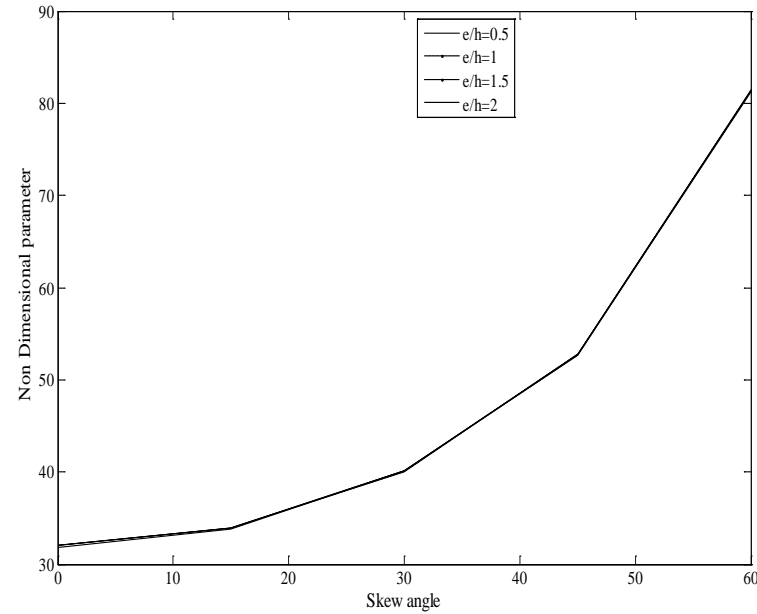

Fig. 8. Variation of frequency parameter with different skew angles for isotropic skew plates with stiffener located at upper edge and $\mathrm{a} / \mathrm{b}=$ 0.5 for CCFF boundary conditions

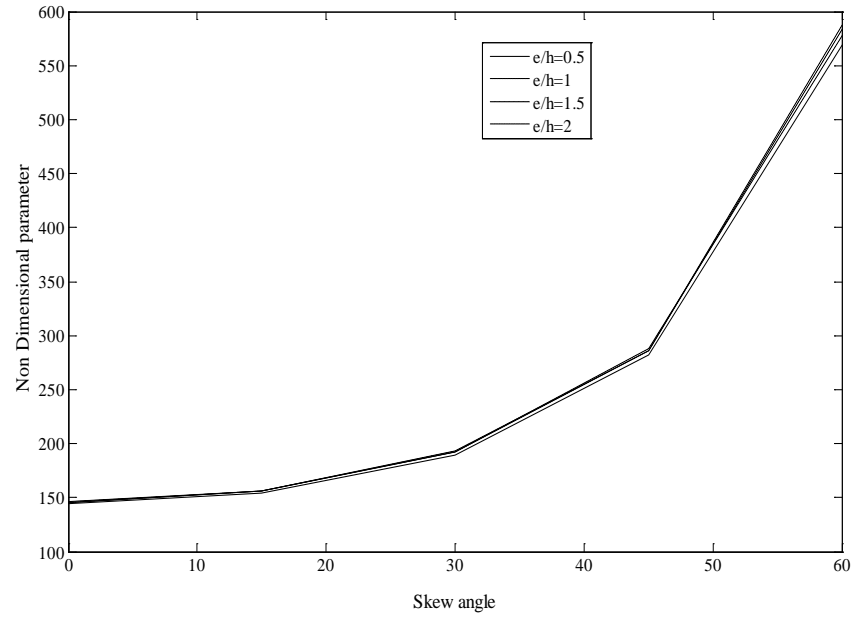

Fig. 9. Variation of frequency parameter with different skew angles for isotropic skew plates with stiffener located at upper edge and $\mathrm{a} / \mathrm{b}=2$ for CCCC boundary conditions

\section{Conclusions}

The finite element methodology has been used to investigate the free vibration analysis of stiffened plates with stiffeners with adequate results. The all edges clamped boundary conditions gives the higher natural frequencies than the other boundary conditions. From the results it is observed that by increasing the skew angle the natural frequency increases and by increasing the stiffener to the plate thickness the natural frequencies also increases for all the boundary conditions. By providing the stiffener to the plate the natural frequencies of the plate shifted towards the higher side. The effect of various types of stiffeners (Types 1, 2, 3 and 4) on the natural frequencies has been studied.

\section{References}

Aksu, G. \& Ali, R. (1976). Free vibration analysis of stiffened plates using finite difference method. Journal of Sound and vibration, 48, 15-25.

Barton, M.V. (1951). Vibration of rectangular and skew cantilever plate. Journal of Applied Mechanics, 18, 129-134.

Bardell, N. S. and Mead, D. J. (1989). Free vibration of an orthogonally stiffened cylindrical shell, part i: discrete line simple supports. Journal of Sound and Vibration, 134 (1), 29-54.

Dawe D.J. (1966). Parallelogrammic elements in the solution of rhombic cantilever plate problems. Journal of Strain Analysis, 1 (3).

Gorman, D. J. (1976). Free vibration analysis of cantilever plates by the method of superposition. Journal of Sound and Vibration 49, 453-467.

Gupta, B. V. R., Ganesan, N. \& Narayanan, S. (1986). Finite Element Free Vibration Analysis of damped stiffened panels. Computers and Structures 24 (3), 485-489.

Hamedani, S. J., Khedmati, M. R. \& Azkat, S. (2012). Vibration analysis of stiffened plates using finite element method. Latin American Journal of Solids and Structures, 9, 1 - 20.

Laura, P. A. A. \& Gutierrez, R. H. (1976). A note on transverse vibrations of stiffened rectangular plates with edges elastically restrained against rotation. Journal of Sound and Vibration, 48, 15-25.

Leissa, A.W. (1973). The free vibration of rectangular plates. Journal of Solids and Vibration, 31 (3), 257-293.

Liu, W. H. \& Chang, I. B. (1989). Some studies on the free vibration of cantilever plates with uniform and non-uniform thickness. Journal of Sound and Vibration, 130, 337-341. 
Liu, W. H. \& Chang, I. B. (1990). Deflections and vibrations for cantilever plate with stiffeners. Journal of Sound and Vibration, 136, 511-518.

Liu, W.H. \& Chen, W.C. (1992), Vibration analysis of skew cantilever plates with stiffeners. Journal of Sound and Vibration, 159 (1), 1-11.

Mizusawa, T. Kajita, T. \& Naruoka, M. (1979). Vibration of skew plates by using B-spline function. Journal of Sound and Vibration, 62, 301-308.

Mukherjee, A. \& Mukhopadhyay, M. (1988). Finite element free vibration of eccentrically stiffened plates. Computers and Structures, 30 (6), 1303-1317.

Mustafa, B.A.J. \& Ali, R. (1987). Free vibration analysis of multi-symmetric stiffened shells. Computers and Structures, 27 (6), 803-810.

Nair, P. S. \& Rao, M. S. (1984). On vibration of plates with varying stiffener length. Journal of Sound and Vibration, 95, 19-30.

Qing, G., Qiu, J., \& Liu, Y. (2006). Free vibration analysis of stiffened laminated plates. International Journal of Solids and Structures, 43, 1357-137.

Samanta, A. \& Mukhopadhyay, M. (2004).Free vibration analysis of stiffened shells by the finite element technique. European Journal of Mechanics A/solids, 23, 159-179.

Sharma, A.K. \& Mittal, N.D. (2010). Review on stress and vibration analysis of composite plates. Journal of Applied Sciences, 10 (23), 3156-3166.

Sharma, A.K. \& Mittal, N.D., Sharma A. (2011). Free vibration analysis of moderately thick antisymmetric cross-ply laminated rectangular plates with elastic edge constraints. International Journal of Mechanical Sciences, 53, 688-695.

Sharma, A.K. \& Mittal, N. D. (2013). Free vibration analysis of laminated composite plates with elastically restrained edges using FEM. Central European Journal of Engineering, 3 (2), 306-315.

Sharma, A.K. \& Mittal, N.D. (2014). Free vibration analysis of moderately thick Anti-symmetric angle ply laminated rectangular plates with elastic edge constraints. Mechanics of Advanced Materials and Structures, 21, 341-348.

Sivakumaran, K.S. (1987). Natural frequencies of symmetrically laminated rectangular plates with free edges. Composite Structures, 7, 191-204.

Wu, J.R. and Liu, W. H. (1988). Vibration of rectangular plates with edge restraints and intermediate stiffeners. Journal of Sound and Vibration, 123, 103-113. 